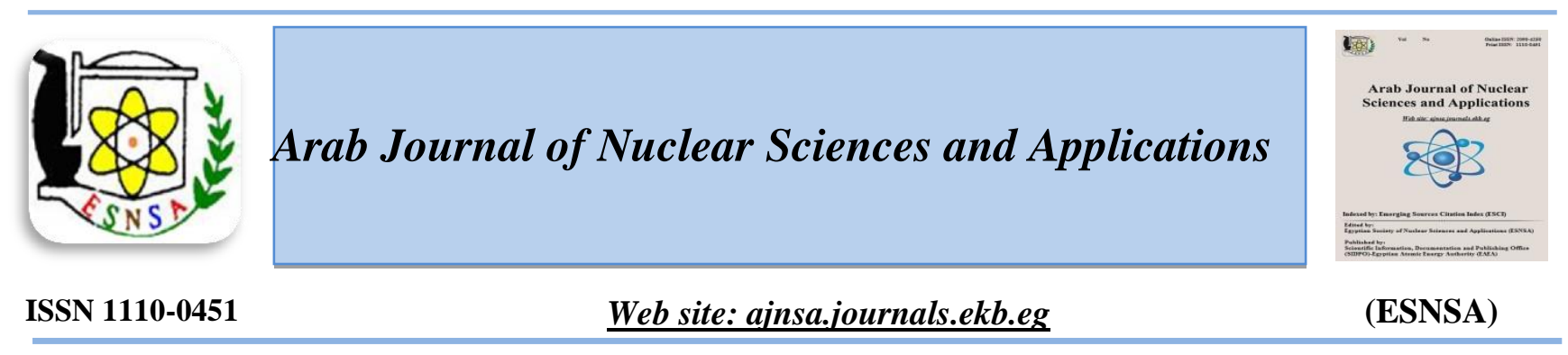

\title{
Electric Field Effect on Soot Formation and Collection from Diffusion Flames
}

\author{
N.M. Abdel-Moniem ${ }^{a}$, S. M. Al Yamany ${ }^{b}$, M. A. Amer ${ }^{a}$, and M. A. Fahmy ${ }^{b}$ \\ ${ }^{(a)}$ Physics Department, Faculty of Science, Tanta University, Egypt \\ ${ }^{(b)}$ National Center for Radiation Research and Technology, Atomic Energy Authority, Egypt
}

Received $8^{\text {th }}$ Jun. 2018 The characterization of combustion-formed particulate matter for possible applications as Accepted $8^{\text {th }}$ Dec. 2018 optoelectronic organic materials is studied. A copper probe is inserted at different heights above the burner hole. Probe sampling is followed by collection via particles impactor, containing two main different classes of materials, soot and nanoparticles of organic carbon (NOC). Soot (Carbon) particles are collected from laminar and turbulent diffusion flames by means of a DC electric field in the form of chains and clusters. The great majority of soot particles are found to be positively charged. The I-V characteristics are measured in order to estimate the electrical properties during soot collection. The electric current increases as the collection time increases due to the agglomeration of charged soot particles on the copper probe. It is observed that, the activation energy $\left(\mathbf{E}_{\mathrm{a}}\right)$ increases with increasing of the probe height $(\mathrm{H})$ till reaching to a maximum value. The mobility of ions for soot particles is decreased with the applied potential and increased with the probe height for the turbulent and laminar diffusion flame. The compositions of soot powder samples are investigated by energy dispersive X-ray pattern (EDX) and the size of the soot particles are calculated by dynamic light scattering (DLS) technique.

Keywords: Soot/ Nanoparticles of organic carbon / Combustion

\section{Introduction}

Soot is a particulate matter (PM) produced as a result of incomplete combustion of a hydrocarbon fuel. Ideally, complete combustion of hydrocarbon fuel leads to only carbon dioxide and water, but in practical combustion systems, complete combustion is hard to achieve. With insufficient oxidizer to convert the fuel completely (incomplete combustion), which can be a local or a global phenomenon, other products such as carbon monoxide, hydrogen, and soot exist in addition to carbon dioxide and water. Soot is also formed in the cone of a non-premixed flame as the fuel pyrolyzes, traveling the effect of electric field on kerosene out of the core of the flame toward the oxidizer. Depending upon the residence time and local turbulence, such soot may be incompletely oxidized in the outer cone/tip of the flame.

Diffusion flames were investigated by Amer [14]. The variations of the flame shape and soot emission for acetylene diffusion flame by applying electric field were studied $[5,6]$. The results showed that in the presence of flame, the electric current increased linearly with increasing the applied voltage. Zake and Barmina [7] investigated the electrical control of flame carbon from the propane-air flame soot. The field-enhanced mass transfer of hydrocarbons to the negatively biased electrode in the limit of weak field's leads to the local increase of fuel excess at the vicinity of the electrode that provokes soot growth and deposition. Maricq investigated the size and charge

Corresponding author: dr_nagwa_25@hotmail.com

DOI: 10.21608/ajnsa.2018.4100.1095

(C) Scientific Information, Documentation and Publishing Office (SIDPO)-EAEA 
of soot particles in rich premixed ethylene flames [8]. The charged particles are formed within a limited height range, after their concentration decreases due to neutralization and coagulation. The effect of electric field on hydrocarbon-gas fuel flame had been investigated [9]. The magnitude of the current increased with the magnitude of the applied voltage, where the increased voltage strips more ions from the reaction zone. The prediction of soot formation in laminar opposed diffusion flame was studied [10]. The extraction of soot from a laminar propane flame by means of an electric field was investigated [11]. It is found that the soot layer on the negative rod grows in the form of a branching tree as the time passes, and the soot has a friable integrated structure. The ionic current in the natural gas flames by applying DC voltage was measured [12]. To characterize the ion density and mobility in the flame, the authors applied bipolar DC voltage between two electrodes such as a Bunsen burner and a steel lattice holding in the flame. Altendorfner et al [13] studied the effect of the electric field on emissions and flame stability with optimized electric field geometry, they found that a strong dependency of the field induced reduction of the emission of pollutants on the diameter of the electrode. Försth and Larsson [14] investigated the effect of electric field on a premixed propane flame. Their measurements of the ionic current between two electrodes may be used for the detection of ignition in a cone calorimeter, and for fire dynamics investigations in general. Wang et al [15] studied the effect of a nominally uniform electric field on the initially uniform distribution of soot. They had assessed for laminar premixed ethylene-air flames which were produced with a McKenna burner. Kroner et al [16] studied the measurements of soot particles in dependence of the height above the burner and the distance from the lateral border of the flame. The properties of small particles in flames, a basic description of static and dynamic light scattering measurement techniques, as an example that demonstrate the application of these techniques in flame environments were studied. Belhi et al [17] studied the effect of the electric field on flame stability, and they found that the electrons moved in the opposite direction of the electric field, and the electric field produces a significant body electric force called ionic wind, which decreases the velocity especially at the base of flame, also the increasing of the applied voltage improves the stability by decreasing the lift-off height. The characterization of soot studied by Arnal et al [18] used different techniques like: elemental analysis, Brunauer-Emmett-Teller (BET) or surface area measurement, transmission electron microscope (TEM), scanning electron microscope (SEM) and X-ray diffraction (XRD). P. Lu et al [19] studied the characterization of soot from a ceramic furnace with flow gas using scanning electron microscopy (SEM), energy dispersive spectroscopy (EDS), specific surface area measurements, crystal characterization and organic pollutant analysis. The oxidation of soot particles in the presence of $\mathrm{NO}_{2}$ was studied [20] and where it was found that the $\mathrm{NO}_{2}$ rich atmosphere enhances the soot oxidation at lower temperatures by generation of active surface functional groups. The characteristics of lean combustion of premixed propane flame with adding $\mathrm{H}_{2}$ and $\mathrm{CO}$ on a Vshaped impinging burner were experimentally investigated [21].

The present study aims to understand the interaction of the electric field and diffusion flames, as it suggests a possible route to combustion control. Studies of physical and chemical properties of collected soot by different characterization methods are presented.

\section{Experimental Procedure}

The circuit used in this study is shown in Figure. (1). The used fuel is gasoline which is combusted on a wick burner in the normal conditions at room temperature and atmospheric pressure to generate laminar or turbulent diffusion flames. The DC voltage $(\mathrm{V})$ is applied to the copper probe as the negative electrode holding in the flame at different heights.

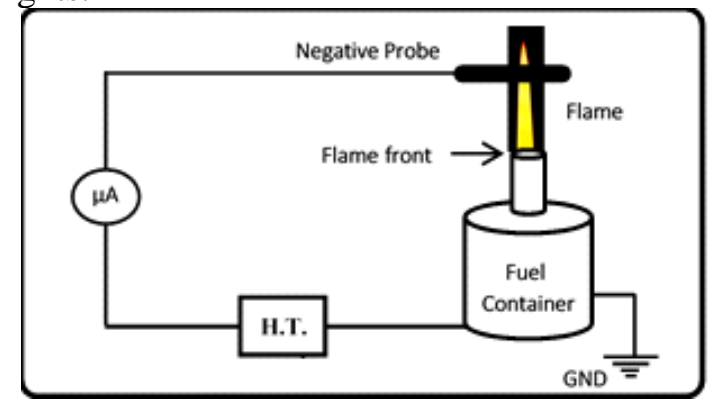

Figure (1) Schematic diagram of the experimental setup

Soot particles are generated in the form of chains and clusters by the combustion of commercial gasoline fuel. The electrical characteristics obtained from this circuit can be used to estimate 
the mass of soot particles, and electrical behavior of collected material [22-24]. Measurements are carried out on the flame nature and its electrical properties. It is found that the flame contains charged particles, and most of them are positively charged. The negative copper probe is placed in the flame to collect the charged carbon ions. The probe height $(\mathrm{H})$ over the flame front is changed to study the characteristics of ionic current (I) with the applied electric voltage (V). As the power supply is switched on, both the ionic current (I) and the collected soot on the probe are increased with time (t). After a certain time, the current reaches a the saturation value $\left(\mathrm{I}_{\mathrm{s}}\right)$. The $\mathrm{I}-\mathrm{V}$ characteristics are recorded many times and the average $\mathrm{I}-\mathrm{V}$ value was extracted. The ionic current (I) is measured as a function of collection time (t) at different applied potentials (V) and different heights $(\mathrm{H})$ above the flame front separately.

\subsection{Energy Dispersive X-Ray (EDX)}

Energy dispersive X-ray pattern of the collected soot particles is shown in Figure. (2).

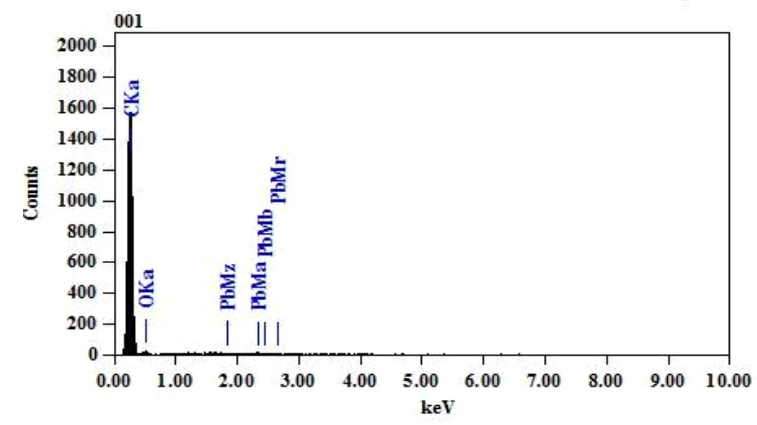

Figure. 2: EDX pattern of soot powder

The samples were found to be composed of carbon, oxygen, and lead with percentages $91 \%, 8$ $\%$, and $1 \%$, respectively, as shown in Table (1).

Table (1): Elements content in soot samples
\begin{tabular}{|l|l|}
\hline Mass \% & Element \\
\hline $91 \%$ & Carbon \\
\hline $8 \%$ & Oxygen \\
$1 \%$ & Lead \\
\hline
\end{tabular}

\section{Results and Discussion}

Carbon particulate derived from combustion consists of a variety of organic compounds, which often have features similar to polymers and molecules used as photoactive layers in the most common organic solar cells [25]. This consideration provided the inspiration to check out the possible applications of these products in the photovoltaic technology. In this study, combustion-formed carbonaceous materials are collected from fuel-rich premixed flames of gasoline and air. The flame-formed carbon particulate matter contains two main different classes of materials: soot and nanoparticles of organic carbon (NOC) [26]. To obtain carbon materials with different properties, one sampling procedure is used: probe sampling followed by collection via particles impactor.

\subsection{Probe sampling description}

The experimental combustion system consists of both laminar and turbulent flame burner at atmospheric pressure, used to generate a flame of gasoline and air. In this flame, a copper probe is inserted at different heights1, 2, 3 and $4 \mathrm{~cm}$ above the burner hole, the probe consists of a copper tube $12 \mathrm{~cm}$ long, with a hole (diameter $=1 \mathrm{~cm}$ ) and connected to a particles impactor (probe), that is collected particles with a given distribution function.

\subsection{Current-voltage-time characteristics}

The relation between the electric current generated in flame and soot collection time at different applied voltages for laminar and turbulent diffusion flames is shown in Figures. ( $3 a$ and b), respectively.

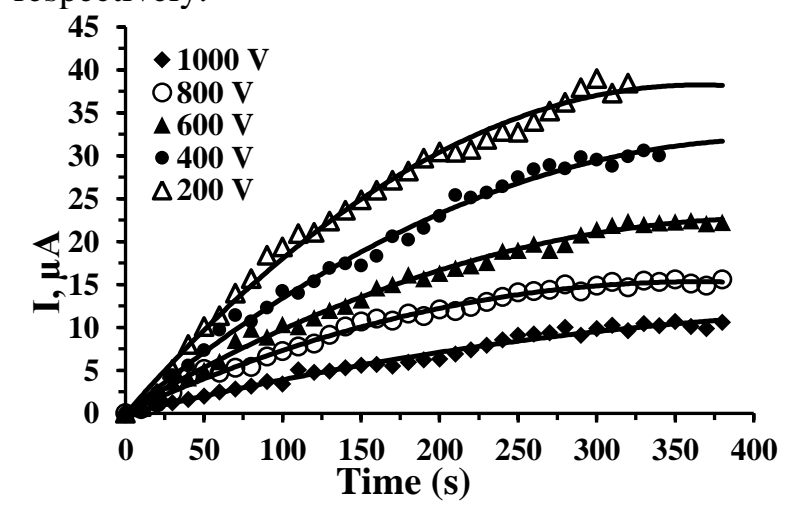

Figure (3a): Ionic current Vs time for laminar flame at probe height $3 \mathrm{~cm}$ and different voltages. 


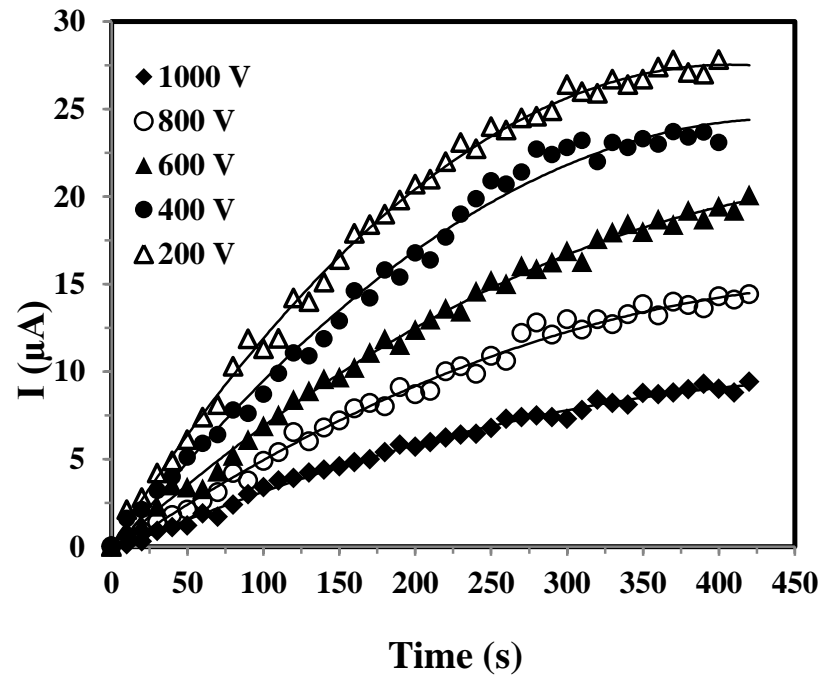

Figure (3b): Ionic current Vs time for turbulent flame, at probe height $3 \mathrm{~cm}$ and different voltages

The electric current is increased as the collection time increases due to the agglomeration of charged soot particles on the copper probe. Most of soot particles are found to be positively charged, so the copper probe is connected as a negative probe in the electric circuit. The current reaches nearly saturation at a certain time for different voltages. Figureures ( 4 a and b) represent the I-V characteristics curves of soot particles at different probe heights

for laminar and turbulent flames respectively. The I-V curves show Ohmic behavior up to $150 \mathrm{~V}$, so the resistance of the soot particles can be determined. Above $150 \mathrm{~V}$, the non Ohmic behavior started. At constant voltage, it is noticed that, the current is increased with decreasing of height $(\mathrm{H})$ as mentioned in [27, 28].

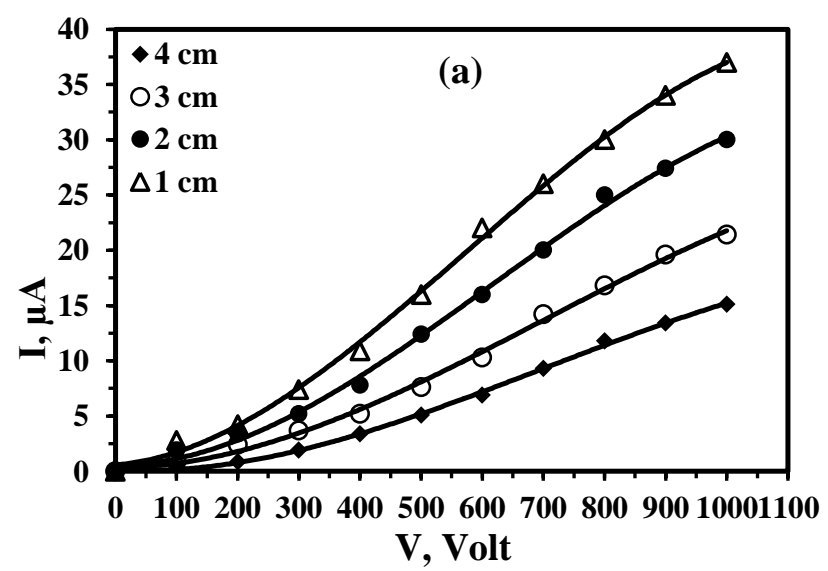

Figure. (4a): Current-voltage characteristics for laminar flame at different probe heights $(\mathrm{H})$

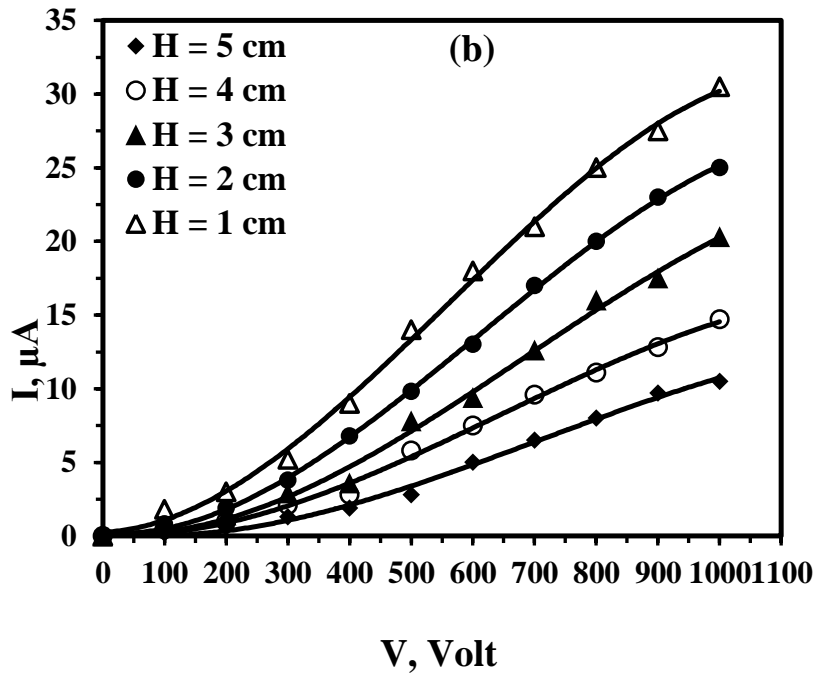

Figure. (4b): Current-voltage characteristics for turbulent flame at different probe heights $(\mathrm{H})$

\subsection{The activation energy of soot particles}

The activation energy for soot particles deposited from the diffusion flame of gasoline fuel can be deduced using Arrhenius' law as;

$I_{S}=I_{0} e^{\frac{-E_{a}}{e V}}$

Where, $I_{s}$ is the saturation current, $I_{o}$ is the space charge current, $E_{a}$ is the acquired activation energy of charged soot particles to move toward the negative probe under effect of applied voltage, e is the charge of electron, and $\mathrm{V}$ is the electric voltage.

The fitting of Figures. ( $5 \mathrm{a}$ and $\mathrm{b}$ ) have negative slopes indicating that the values of acquired activation energies are 343 and $360 \mathrm{eV}$, respectively. These values are less than the experimental data by $\approx 17 \%$.

The relation between activation energy of soot deposition and the probe height $\mathrm{H}$ along the flame axis is shown in Figures. ( 6 a and b) for laminar and turbulent flames, respectively. It is shown that 


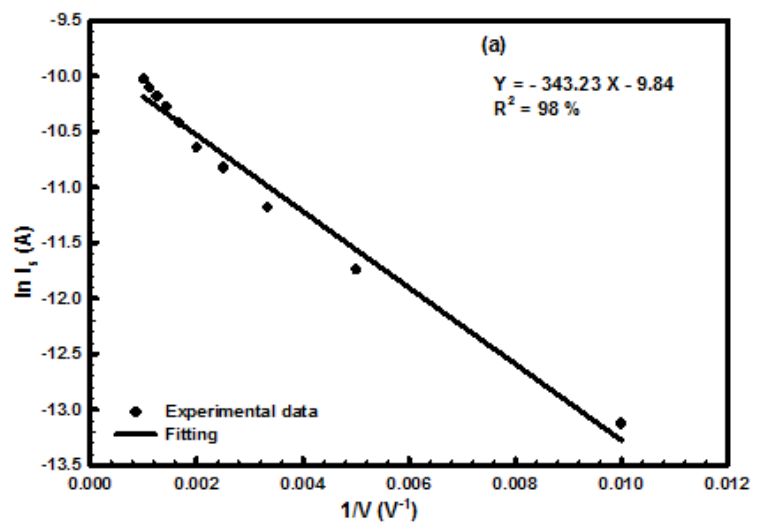

Figure. (5a): (ln $\left.I_{S}\right)$ and (1/V), at probe height $2 \mathrm{~cm}$ for laminar flame

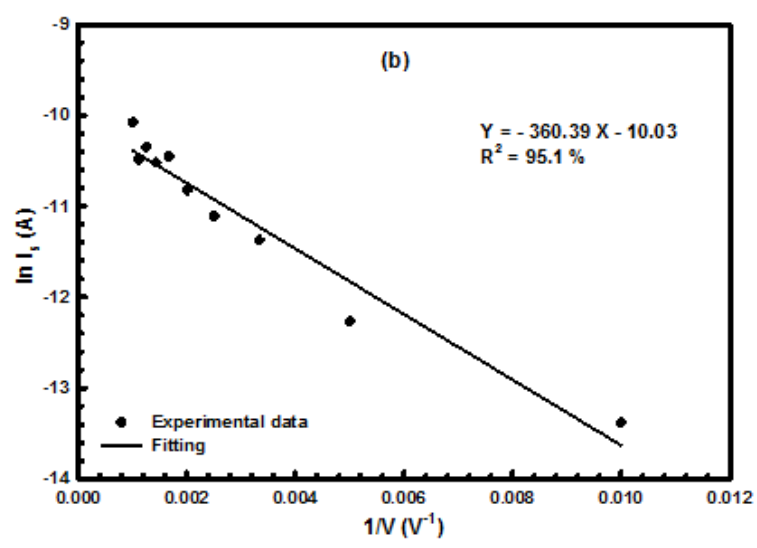

Figure. (5b): (ln $\left.I_{S}\right)$ and (1/V), at probe height $2 \mathrm{~cm}$ for turbulent flame

the activation energy $E_{a}$ is increased with increasing probe height $(\mathrm{H})$ at $700 \mathrm{~V}$. This is may be due to the decrease of the flame temperature which in turn requires more thermal energy.

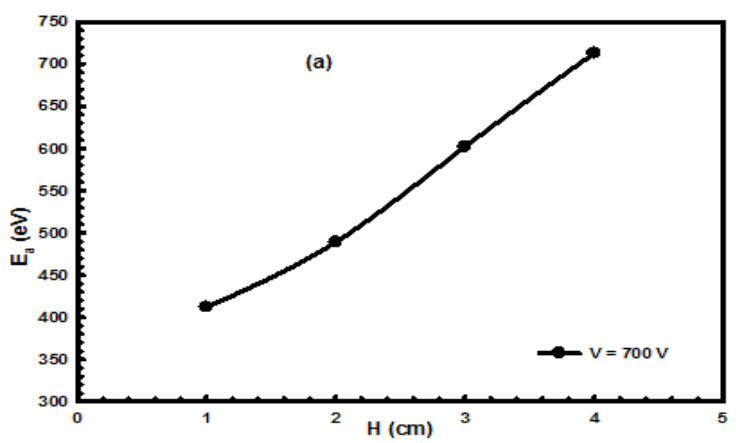

Figure. (6a): Relation between the activation energy $E_{a}$ and probe height $\mathrm{H}$, for: laminar flame

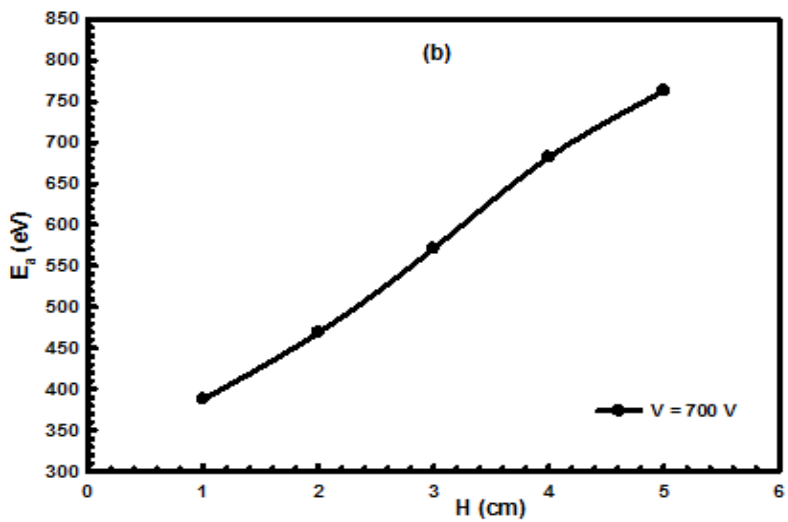

Figure. (6b): Relation between the activation energy $E_{a}$ and probe height $\mathrm{H}$, for turbulent flame

\subsection{The Mobility of soot particles}

The mobility of soot particles is calculated from the following equation:

$$
J=\frac{9 \mu V^{2}}{32 H^{3}}
$$

Where, $J$ is the current density and $\mu$ is the ion mobility.

Figureures ( $7 \mathrm{a}$ and $\mathrm{b}$ ) show the change of ions mobility with the applied electric voltage. The mobility of ions decreases with the applied potential and increases with the probe height for the laminar (a) and turbulent (b) diffusion flames as shown in these Figureures. The force affected on the ions increase by increasing the applied voltage on these ions. As a result, the mobility of ion decreases by increasing the applied voltage. As a comparison, the mobility of ions in nonpremixed diffusion flame, which ranges from $4.5 \times 10^{-10}$ to $2 \times 10^{-8} \mathrm{~cm}^{2} \mathrm{~V}^{-1} \mathrm{sec}^{-1}$, is less than the mobility values of some premixed flames, which are reported from $10^{-3}$ to $3 \times 10^{-2} \mathrm{~cm}^{2} \mathrm{~V}^{-1} \mathrm{sec}^{-1}$ as mentioned in $[29,30]$.

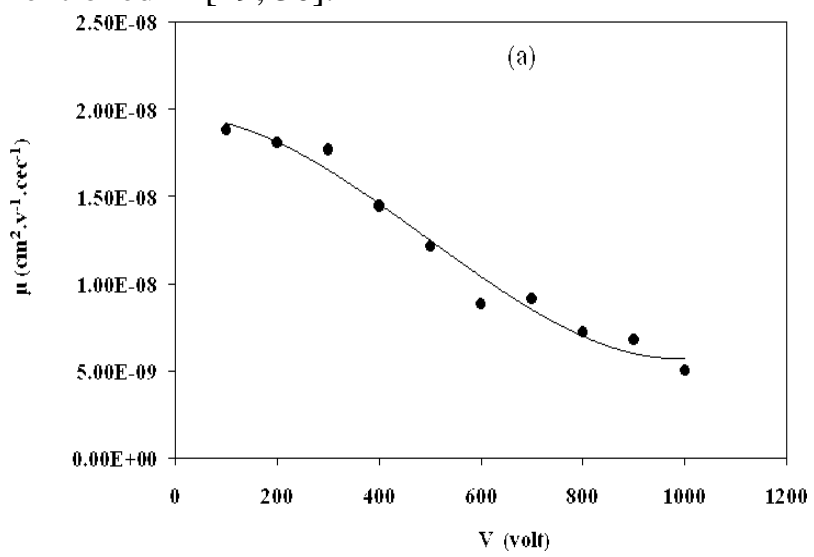

Figure. (7a): Mobility of carbon ions $(\mu)$ Vs electric voltage $V$, for laminar flame at probe height $3 \mathrm{~cm}$ 


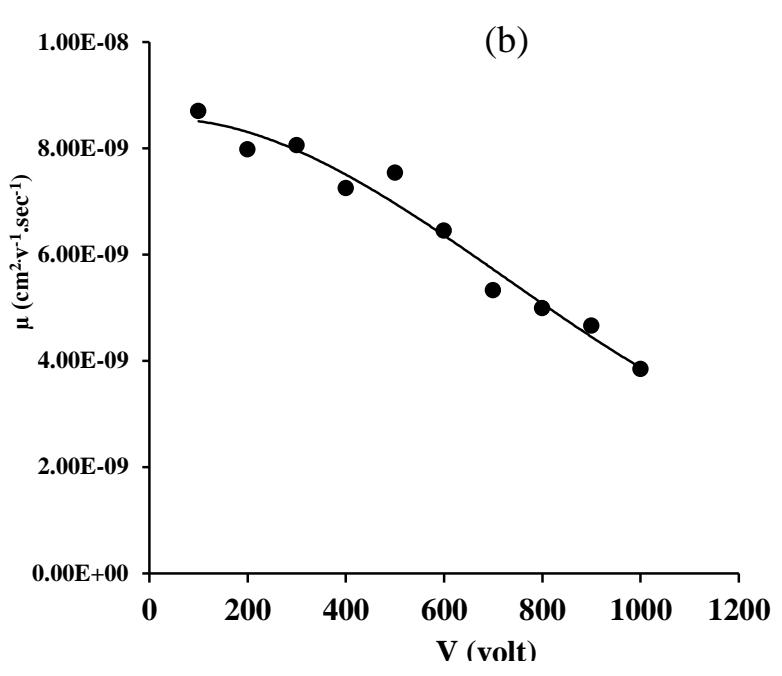

Figure(7b):Mobility of carbon ions ( $\mu$ ) Vs. electric voltage $V$, for turbulent flame at probe height $3 \mathrm{~cm}$

\subsection{Dynamic Light Scattering}

Dynamic Light Scattering (DLS) is an important tool for characterizing the size of nanoparticles in a solution. DLS measures the light scattered from a laser that passes through a colloidal solution and analyzing the modulation of the scattered light intensity as a function of time. Small particles in suspension undergo random thermal motion known as Brownian motion. This random motion is modeled by the Stokes-Einstein equation. This equation relates the diffusion coefficient $D_{t}$ with the radius of particles as follow [31]:

$$
D_{t, \text { avg }}=\frac{K_{B} T}{3 \pi \eta d_{z}}
$$

Where, $d_{z}$ is the hydrodynamic diameter (this is the goal: particle size), $D_{t, \text { avg }}$ is the translational diffusion coefficient (by DLS), $\mathrm{K}_{\mathrm{B}}$ is Boltzmann's constant (known), $\mathrm{T}$ is thermodynamic temperature in Kelvin (solution temperature) and $\eta$ is dynamic viscosity (water $0.933 \mathrm{cp}$ ).

The translational diffusion coefficient $D_{t}$ may be derived at a single angle or at a range of angles depending on the wave vector q. The decay rate $\boldsymbol{\Gamma}$ is given by [32];

$$
\Gamma=q^{2} D_{t}
$$

$$
\text { Where } q=\frac{4 \pi n}{\lambda} \sin \left(\frac{\theta}{2}\right) \text {, }
$$

$\mathrm{n}$ is the refractive index of the sample (1.33), $\theta$ is the angle at which the detector is located with Arab J. Nucl. Sci. \& Applic. Vol. 52, No. 1 (2019) respect to the sample cell $\left(90^{\circ}\right)$ and $\lambda$ is the incident laser wavelength $(632.8 \mathrm{~nm})$. The cumulated analysis, as mentioned in [33], can only determine the particle size distribution of a Gaussian distribution around a mean particle size as in Table (2)

Table (2): Cumulative results

\begin{tabular}{|c|c|}
\hline Distribution \% & Diameter, $\mathrm{nm}$ \\
\hline 25 & $<95$ \\
\hline 50 & $<130$ \\
\hline 75 & $<178$ \\
\hline 90 & $<237$ \\
\hline 99 & $<387$ \\
\hline 100 & $<4006$ \\
\hline
\end{tabular}

The intensity distribution is closest to the raw data. The volume distribution corresponds to results derived from methods where concentrations are measured [34]. The Z-Average size or Z-Average mean used in dynamic light scattering is a parameter also known as cumulates mean. It is the primary and most stable parameter produced by the technique. It should be noted that the Z-average is a hydrodynamic parameter and is therefore only applicable to particles in dispersion or molecules in solution [35]. The Z-average in this paper is found to be $1.6 \times 10^{-8} \mathrm{~cm}^{2} / \mathrm{sec}$. This is a simple method of analyzing the autocorrelation function generated by a DLS experiment [32]. A second important number is the polydispersity index which is a measure of the width of the particle size distribution. Polydispersity indices less than 0.1 are typically referred to as "monodisperse". The formula for Polydispersity is

$P D I=\left(\frac{\sigma}{d}\right)^{2}(5)$

Where $\sigma$ is the standard deviation and $d$ is the mean diameter. This index is a number calculated from two simple parameters fit to the correlation data (the cumulated analysis). The Polydispersity Index is dimensionless and scaled such that values smaller than 0.05 are rarely seen other than with highly monodisperse standards. It is found that these results have a polydispersity index of 0.25 and this is due to a broad size distribution. All the distributions are summarized in Table (3). 
Table (3): DLS Data of Different Gaussian Distribution Analysis of soot suspension

\begin{tabular}{|c|c|c|c|}
\hline Number & Volume & Intensity & Parameter \\
\hline 144 & 467 & 401 & $\begin{array}{c}\text { Mean Diameter } \\
(\mathrm{nm})\end{array}$ \\
\hline 68 & 220 & 189 & $\begin{array}{c}\text { Standard Deviation } \\
(\mathrm{nm})\end{array}$ \\
\hline \multicolumn{3}{|c|}{$\sim 379 \mathrm{~nm}$} & $\begin{array}{c}\text { Particle size by } \\
\text { DLS }\end{array}$ \\
\hline \multicolumn{3}{|c|}{0.25} & $\begin{array}{c}\text { polydispersity } \\
\text { index }\end{array}$ \\
\hline
\end{tabular}

However, normal standard deviation is 0.5 , Zaverage differential coefficient is $1.16 \times 10^{-8} \mathrm{~cm}^{2} / \mathrm{s}$, laser beam wavelength is $623 \mathrm{~nm}$, at temperature $23^{\circ} \mathrm{C}$, viscosity is 0.933 , and the refractive index of reference is 1.333 .

\section{Conclusion}

Soot (Carbon) particles have been collected from laminar and turbulent diffusion flames by means of a DC electric field in the form of chains and clusters. The great majority of soot particles have been found to be positively charged. The analysis of different combustion-formed carbonaceous materials has been carried out by investigating electrical and thermal properties. Soot during collection has a low electrical conductivity. The agglomeration of charged soot particles on the copper probe causes an increase in the electric current with the collection time till reaching a saturation value. The applied electric voltage enhances the process of soot collection. The activation energy is increased with increasing the probe height till reaching to a maximum value. The mobility of ion decreases by increasing the applied voltage. Also, the mobility of ions in nonpremixed diffusion flame is less than mobility values of some premixed flames. Energy dispersive X-ray (EDX) proves that soot samples are composed of carbon, oxygen, and lead with percentages $91 \%, 8 \%$, and $1 \%$, respectively. Dynamic light scattering (DLS) shows that, the average hydrodynamic diameter of soot particles is $379 \mathrm{~nm}$. Also, the diameter of about $25 \%$ of soot particles is less than $95 \mathrm{~nm}$.

\section{References}

1-Amer, M.A., (1992) proc. 4th National Phys. conf., Cairo Univ., Cairo, Egypt 233.

2-Amer, M.A., (1993), proc. 3ed conf. (internal) on "Envir. Prot. is a must", Alex. Univ., Alex., Egypt, 13.
3-Amer, M.A, (1994) proc. $4^{\text {th }}$ conf. (internal) on "Envir. Prot. is a must", Alex. Univ., Alexandria, Egypt, 629.

4-Amer, M.A., (1994) proc. 4th conf. (internal) on "Envir. Prot. is a must", Alex. Univ., Alex., Egypt, 611.

5-Saito, M., Arai, T., and Arai, M., (1999) Combustion and Flame, 119, pp 356.

6-Saito, M., Sato, M., and Sawada, K., (1997) Electrostatics, 39, pp 305.

7-Zake, M., and Barmina, I., (2001) Int. Sci. Colloq., pp 198

8-Maricq, M.M., (2004) Combustion and Flame 137, pp 340-350

9-Yuan, Z.G. and Hegde, U., (2003) NASA. Cp. NCC3-544, pp 305.

10-Chang, H. (2004) Sch. of Aerospace Eng., Inst. of Tech., Georgia.

11-Vatazhin, A.B., Golentsov D.A. and Likhter, V. A. (2005) Fluid Dynamics, 40, pp 172.

12-Winkler, L., Hegman, N., Raffay C., and Palotás, A.B. (2007) European Combust. Meeting, 1.

13-Altendorfner, F., Sakhrieh, A., Beyrau, F. Leipertz, A., Dinkelacker, Lins, F. Hammer, G. T. and Branston, D. W., (2007) third Europ. Combust. Meeting (ECM), 1.

14-Försth, M. and Larsson, A., (2010) Fire and Material, 34, pp 421.

15-Wang, Y., Nathan, G.J., Alwahabi,Z.T. King, Ho D. K. and Yao, Q., (2010) Combust. Flame, 157, pp1308.

16-Kroner, G. , Fuchs, H. , Tatschl, R. and Glatter, O., , (2003) Aerosol Science and Technology, Volume 37, Issue 10.

17-Belhi, M., Domingo, P. and Vervisch, P., (2010) Combust. Flame, 157, pp 2286.

18-Arnal, C. Alzueta, M.U., Millera, A. and Bilbao, Chia. R., (2011). Laguna, Cagliari, Sardinia, Italy, September 11-15, MCS 7.

19-Lu, P., Li, C. Zeng, G. Xie, X., Cai, Z., Zhou, Y., Zhao, Y., Zhan, Q., Zeng, Z., Hazardous, J. (2012) Mater., 199, pp 272.

20-Müller, J.O. Frank, B. Jentoft, R.E., Schlögl, Sheng Su, R. D., (2012)Catalysis Today, 191, pp 106-111.

21-Chen, J.W. Chiu, C.P. Mo, S.H. Yang, J.T., (2015) international journal of hydrogen energy, 40, pp 255.

22-Ohisa, Kimura, H.I. and Horisawa, H., (1999) Combust. Flame, 116, pp 653. 
23-Bruschi, P. Nannini, A., (1991) Thin solid films, 201, pp 29-38.

24-Glen, G.D., (1996) Master's Thesis, Miami Univ.

25-D’Anna, A., (2009) Proc. Comb. Inst., 32, pp 593-613.

26-Adkins, C.J. (1982) J. Phys. C 15, pp 71437155

27-Bruschi, P. Nannini, A., (1991), Thin solid films, 201, pp 29-38.

28-De Falco, G., Commodo, M., Bonavolontà, C. Pepe, G.P., Minutolo, P., D’Anna, A., (2014) Comb. Flame, Conference: XXXIV Meeting, Italian Sec. of Comb. Inst.

29-Dec., J.E. (1997). SAE Technical Paper series, 970873.

30-Weinberg, F.J., Lawton, J. and Mayo, P.J., (1968) Proc. Roy. Soc. London, A. 303, pp 275.

31-Atkins, Peter, Julio De Paula (2010)."Physical Chemistry" $9^{\text {th }}$ ed., Oxford: Oxford UP.

32-Johnson, C.S., Gabriel, D.A., (1981) Inc., New York.

33-Frisken, J. Barbara (2001) Applied Optics. 40 (24), pp 4087-91.

34-Dahneke, B.E., (1983)"Measurement of Suspended Particles by Quasi-elastic Light Scattering", Wiley.

35-Washington, C., (1992)"Particle Size Analysis in Pharmaceutics and Other Industries: Theory and Practice", Ellis Horwood, England. 